Revue d'histoire de l'Amérique française

सES REVUE D.HISTOIRE DE L'AMÉRIQUE FRANÇAISE

\title{
Le Révérend Père Jacques Marquette, S.J. était-il prêtre?
}

\section{Jean Delanglez}

Volume 2, numéro 4, mars 1949

URI : https://id.erudit.org/iderudit/801504ar

DOI : https://doi.org/10.7202/801504ar

Aller au sommaire du numéro

Éditeur(s)

Institut d'histoire de l'Amérique française

ISSN

0035-2357 (imprimé)

1492-1383 (numérique)

Découvrir la revue

Citer ce document

Delanglez, J. (1949). Le Révérend Père Jacques Marquette, S.J. était-il prêtre? Revue d'histoire de l'Amérique française, 2(4), 581-582.

https://doi.org/10.7202/801504ar d'utilisation que vous pouvez consulter en ligne.

https://apropos.erudit.org/fr/usagers/politique-dutilisation/ 


\section{LE RÉVÉREND PĖRE JACQUES MARQUETTE, S.J. ÉTAIT-IL PRETTRE?}

La Revue de l'Université Laval (janvier 1949) a publié un article de six pages, où l'auteur prétend démontrer que Jacques Marquette n'était pas prêtre. On a aussi reproduit en photographie l'attestation du sous-archiviste, selon laquelle les registres de l'archevêché, de 1666 a 1675, ne contiendraient nulle trace de l'ordination de Jacques Marquette. Voilà qui est intéressant. Pour plaire à l'auteur, faudrait-il ordonner le Père une seconde fois? On explique que Jacques Marquette "was the baby boy of [a] powerful wealthy family ", et que cette famille aurait " staged a grand celebration on the occasion of their son's first Mass ". L'article contient quelques autres détails de même nature; notre dessein n'est pas de nous y attarder.

Voici les faits. Le 20 septembre 1666, « le $P$. Jacques Marquette arrive [à Québec] en bonne santé »; le 10 octobre suivant, "le $P$. Jacques Marquette monte aux Trois-Rivières "); et le 21 avril 1668, " le $P$. Marquette " s'apprête à partir pour les missions de l'Ouest. (Le Journal des Jésuites, pp. 350, 351, 360). Qu'on n'aille pas dire que Laverdière et Casgrain, les éditeurs du Journal, ont fait erreur. Partout ailleurs, quand il est question de Frères, par exemple, p. 5, 85, 89, 93, 106, etc., on lit " $F$ » et quand il s'agit de Père on lit " P. " Dans les Relations des Jésuites, il n'est fait mention que du Père Marquette. Pendant les neuf ans qu'il passa au Canada, tous ceux qui l'ont connu ne l'appellent pas autrement. Il a fallu attendre 275 ans pour entendre dire qu'il n'a jamais été ordonné.

Il y a mieux encore. Dans son second voyage au pays des Illinois, le Père Marquette tint un journal, reproduit en photographie et imprimé par Thwaites dans ses Jesuit Relations. Qu'y lisons-nous? Le 1er novembre 1674, " ayant dit la Sainte Messe... "; puisqu'ils n'étaient que trois, Jacques Largilier, Pierre Porteret et Jacques Marquette, qui a dit cette Messe? Ni Largilier, ni Porteret, car, on 
le sait, tous deux étaient des donnés. Alors? Le 9 février nous lisons: " Depuis que nous sommes adressés à la Sainte Vierge Immaculee, que nous avoos commencé une neuvaine par une messe à laquelle Pierre [ Porteret ] et Jacques [ Largilier ]... ont communié pour demander à Dieu la santé »). Qui avait dit cette messe et qui avait consacré ces hosties? Le 30 mars Marquette écrit encore: " Mon mal ne m'ayant point empêché de dire la Sainte Messe tous les jours ". Il y a dans ce jouraal, relativement court, cinq autres mentions explicites de messes dites. Parce que le Père Marquette " was the baby boy of [ a ] powerful wealthy family "), faudra-t-il croire qu'on l'ait laissé dire la messe sans être ordonné? Enfin la lettre obituaire, un autographe du Père Dablon, porte au coin supérieur, à droite, de l'écriture au Père Ragueneau, cette annotation: "Let[ $t$ ]re circulaire du P. Marquette "; et Dablon commence par ces mots: "Celle-ci est pour donner avis à Votre Révérence de la mort du Père Jacques Marquette... " Que la Revue de l'Université Laval ait publié cet article sans vérifier les faits, nous paraît une éaigme.

\author{
Jean Delanglez, S.J. \\ Professeur d'histoire, Loyola University, Chicago.
}

N.B. - Faute d'espace, nous nous excusons, auprès de nos lecteurs et des auteurs, de n'avoir pu publier, dans cette livraison, deux articles fort intéressants : De Montréal en Bugey à Montréal au Canada, par le Dr Pierre Gauthier (Bourg-en-Bresse, France); et La Mission de l'abbé Thomas Maguire à Rome en 1833-1834, par l'abbé Antonio Dansereau, p.s.s., Montréal. - Ce sera pour notre no de juin. 